Mat. Res. Bull., Vol. 28, pp. 685-692, 1993. Printed in the USA.

0025-5408/93 \$6.00 +.00 Copyright (c) 1993 Pergamon Press Ltd.

\title{
STRUCTURE AND OXYGEN STOICHIOMETRY IN COMPLEX NEODYMIUM STRONTIUM COBALT COPPER OXIDES: $\left[\mathrm{NdSrCo}_{1 \cdot x} \mathrm{Cu}_{x} \mathrm{O}_{4 \cdot-y}\right]$
}

D. Grandjean and M.T. Weller

Department of Chemistry.

The University of Southampton SO9 5NH, United Kingdom

(Received March 23, 1993; Communicated by J.B. Goodenough)

\begin{abstract}
Compounds from the solid solution $\mathrm{NdSrCo}_{1-x} \mathrm{Cu}_{x} \mathrm{O}_{4-y}(0 \leq x \leq 0.9)$ have been prepared and characterised with powder $X$-Ray and neutron diffraction together with thermogravimetric analysis. The materials have been shown to adopt the $\mathrm{K}_{2} \mathrm{NiF}_{4}$ structure (spacegroup $14 / \mathrm{mmm}$ ). Variations of the $\mathrm{a}$ - and $\mathrm{c}$ - parameters show a complex behaviour with increasing copper content. At all values of $x$, the average transition-metal oxidation is high. The changes in cell parameters are discussed in terms of oxygen stoichiometry and transition-metal oxidation state from the perspective of the Brown bond valence calculation theory.
\end{abstract}

MATERIALS INDEX: MEODYMIUM, STRONTIUM, COBALTATES, CUPRATES.

\section{Introduction}

Oxides of the $A_{2} M_{4}$ type with $A=L n, M=C u, N i$, Co (1-6), possessing $K_{2} \mathrm{NiF}_{4}$ type structures have been extensively studied in recent years as a result of their electronic and magnetic properties. In fact, $\mathrm{La}_{1.85} \mathrm{Ba}_{0.15} \mathrm{CuO}_{4}$, the barium doped analogue of $\mathrm{La}_{2} \mathrm{CuO}_{4}$ was the first high-Tc oxide discovered with a Tc in the range of $30 \mathrm{~K}$ (1). Whilst $\mathrm{La}_{2} \mathrm{CuO}_{4}$ possesses an orthorhombic distortion of the tetragonal $\mathrm{K}_{2} \mathrm{NiF}_{4}$ structure ( $\mathrm{T} / \mathrm{O}$ type), materials of the same stoichiometry but with lanthanum replaced by the lanthanides $\mathrm{Pr}$ to $\mathrm{Gd}$ crystallise with a different tetragonal structure subsequently referred to as that of $\mathrm{Nd}_{2} \mathrm{CuO}_{4}\left(\mathrm{~T}^{\prime}\right.$ type) (7). In this structure the oxygen has moved from the $0,0, z(z \approx 0.15)$ position in $\mathrm{La}_{2} \mathrm{CuO}_{4}$ to a $0,1 / 2, z$ position in $\mathrm{Nd}_{2} \mathrm{CuO}_{4}$ changing the coordination number of the trivalent cation from 9 in $\mathrm{La}_{2} \mathrm{CuO}_{4}$ to 8 in $\mathrm{Nd}_{2} \mathrm{CuO}_{4}$ and the copper from 6 to 4 . All these compounds, which contain infinite $\mathrm{CuO}_{2}$ layers with copper, basically, in square planar-oxygen coordination separated by 
$\mathrm{Ln}_{2} \mathrm{O}_{2}$ planes, have long been known to exhibit a significant range of nonstoichiometry in oxygen content. Doping these parent compounds with strontium or cerium respectively introduces holes or electrons in the $\mathrm{CuO}_{2}$ sheets to make them superconducting. The solid solutions $\left(\mathrm{La}_{1-x} \mathrm{Sr}_{x}\right)_{2} \mathrm{CuO}_{4-y}$ have been prepared over a wide composition range $(0<x<0.67)(4)$ while $\left(\mathrm{Nd}_{1-x} \mathrm{Sr}_{x}\right)_{2} \mathrm{CuO}_{4-y}$ only exists over a rather more limited composition range $(0.55<x<0.75)(8)$; however both are isostructural with $\mathrm{K}_{2} \mathrm{NiF}_{4}$.

In order to increase the copper oxidation state and to study its evolution with the oxygen stoichiometry, we have prepared a new solid solution $\mathrm{NdSrCo}_{1-x} \mathrm{Cu}_{x} \mathrm{O}_{4-y}$ with higher strontium content by doping both strontium and copper into the parent compound $\mathrm{Nd}_{2} \mathrm{CoO}_{4}$ (9). The structural characterisation of these new compounds was performed either with powder XRD and thermogravimetry for the whole series and for $\mathrm{NdSrCoO}_{4}$ or with powder neutron diffraction for the copper doped samples $\mathrm{NdSrCo}_{1-x} \mathrm{Cu}_{x} \mathrm{O}_{4 . y}$ with $\mathrm{x}=0.2,0.5,0.8$ in order to resolve the oxygen-vacancy distribution.

\section{Experimental}

Samples of nominal composition $\mathrm{NdSrCo}_{1-x} \mathrm{Cu}_{x} \mathrm{O}_{4-y}(0<x<0.9)$ were prepared by direct reaction of $\mathrm{Nd}_{2} \mathrm{O}_{3}(99.9 \%), \mathrm{SrCO}_{3}(99.5 \%), \mathrm{Co}_{3} \mathrm{O}_{4}(99.9 \%)$ and $\mathrm{CuO}(99.9 \%)$ by heating the appropriate well ground mixtures at $970^{\circ} \mathrm{C}$ in air for $48 \mathrm{~h}$. Following regrinding, they were then annealed in air at $1150^{\circ} \mathrm{C}$ for $24 \mathrm{~h}$ and quenched to room temperature.

The oxygen content of the compounds was determined from TGA (thermogravimetric analysis) with a Stanton Redcroft TG1000 series thermobalance by following the weight change on reduction in flowing $5 \% \mathrm{H}_{2}$ in $\mathrm{N}_{2}$ from room temperature to $985^{\circ} \mathrm{C}$ at $25^{\circ} \mathrm{C} / \mathrm{min}$. The copper and cobalt ions are reduced to $\mathrm{Cu}^{\circ}$ and $\mathrm{Co}^{\circ}$ whereas $\mathrm{Nd}^{\mathrm{III}}$ and $\mathrm{Sr}^{\prime \prime}$ keep the same oxidation state.

All phases were characterised by X-ray powder diffraction with a SIEMENS D-5000 $\Theta-2 \Theta$ diffractometer both utilising $\mathrm{Cu} \mathrm{Ka} a_{1}$ radiation. All cell parameters were refined with a least-squares method. The structure of $\mathrm{NdSrCoO}_{4}$ was refined with a Rietveld profile refinement (10). Data for this refinement was collected over a 12 hour period with a step of $0.030^{\circ}$.

Powder neutron diffraction data were collected with POLARIS (11) on ISIS at Rutherford Appleton Laboratory over a timescale of 3 hours at room temperature and refined with a time of flight version of the full-profile Rietveld method $(12,13)$. Refinement was carried out over the time-of-flight range $3500-18500 \mu$ s corresponding to the $d$ spacing values between 0.57 and $3.08 \AA$. Neutron scattering lengths were taken from Koester \& Yelon (1982)(14) as Nd 0.7690, Cu 0.7718, Sr 0.7020 , Co 0.2530 and $00.5805 \times 10^{-12} \mathrm{~cm}$.

\section{Results and discussion}

All the X-ray patterns of the different samples could be indexed in the tetragonal system of $\mathrm{La}_{1.85} \mathrm{Ba}_{0.15} \mathrm{CuO}_{4}$ ( space group $14 / \mathrm{mmm}$ ). The cell parameters resulting from the $X R D$, PND structural studies as well as the oxygen content from TGA measurements are summarized in Table I. The evolution of the cell parameters with the copper content $x$, given in Figure 1 , shows clearly the presence of a change in behaviour at $x \approx 0.4$ both for a and $c$. The major one occurs with the $c$ parameter, which first increases slightly from $12.295 \AA$ to $12.435 \AA$ for $x \approx 0.4$, then increases more rapidly to $12.772 \AA$ for the composition $\mathrm{NdSrCO} \mathrm{O}_{0.1} \mathrm{Cu}_{0.9} \mathrm{O}_{4-\mathrm{y}}$. The second one is observed with the a parameter, which slowly increases from $3.768 \AA$ to $3.778 \AA$ for $x \approx 0.4$ and then decreases rapidly for the higher contents in copper. The plot in Figure 2, presenting the evolution of the oxygen stoichiometry with the copper content, shows that with increasing copper content the level of oxygen remains very close to 4 until the composition $x \approx 0.4$ and then gradually decreases to reach 3.58 for $\mathrm{NdSrCO} \mathrm{O}_{0.1} \mathrm{Cu}_{0.9} \mathrm{O}_{4-\mathrm{Y}^{*}}$ 
TABLE I:

Lattice Parameters and Oxygen Content for all Compositions

\begin{tabular}{||lllll||}
\hline $\begin{array}{l}\text { Copper } \\
\text { content } x\end{array}$ & a parameter $\dot{A}$ & c parameter $\dot{A}$ & $\begin{array}{l}\text { Oxygen } \\
\text { content }\end{array}$ & $\begin{array}{l}\text { Cu oxidation state } \\
\text { (assuming } \text { Co }^{3+} \text { ) }\end{array}$ \\
\hline \hline 0 & 3.773 & 12.295 & 4.00 & -- \\
\hline 0.1 & 3.768 & 12.311 & 4.00 & 3.00 \\
\hline 0.2 & 3.773 & 12.362 & 4.00 & 3.00 \\
\hline 0.3 & 3.776 & 12.393 & 3.99 & 2.93 \\
\hline 0.4 & 3.768 & 12.435 & 3.93 & 2.65 \\
\hline 0.5 & 3.767 & 12.503 & 3.86 & 2.44 \\
\hline 0.6 & 3.766 & 12.569 & 3.84 & 2.47 \\
\hline 0.7 & 3.762 & 12.629 & 3.73 & 2.23 \\
\hline 0.8 & 3.751 & 12.692 & 3.63 & 2.08 \\
\hline 0.9 & 3.744 & 12.772 & 3.58 & 2.07 \\
\hline
\end{tabular}

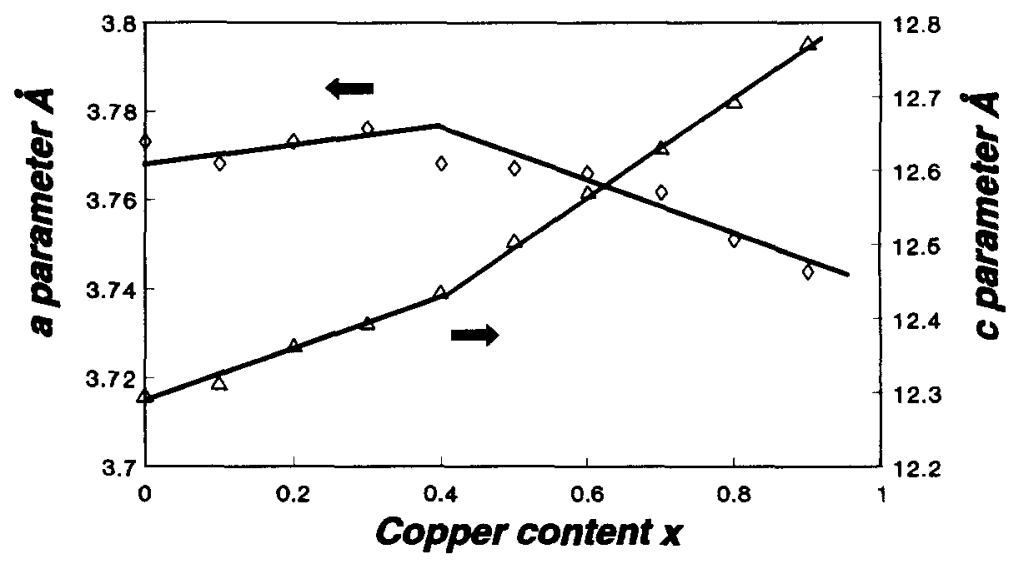

- a parameter $\Delta$ c parameter

FIG. 1 :

a and $c$ Parameter as a Function of the Copper Content

\section{Powder X-Ray Diffraction Refinement of $\mathrm{NdSrCoO}_{4}$}

Full results of the refinement of $\mathrm{NdSrCoO}_{4}$ based on the $\mathrm{La}_{1.85} \mathrm{Ba}_{0.15} \mathrm{CuO}_{4}$ model are given in Table II. The final fit to the profile of the XRD pattern is presented in Figure 3. Attempts to refine the oxygen-site parameters indicated that the two oxygen positions were fully occupied. 


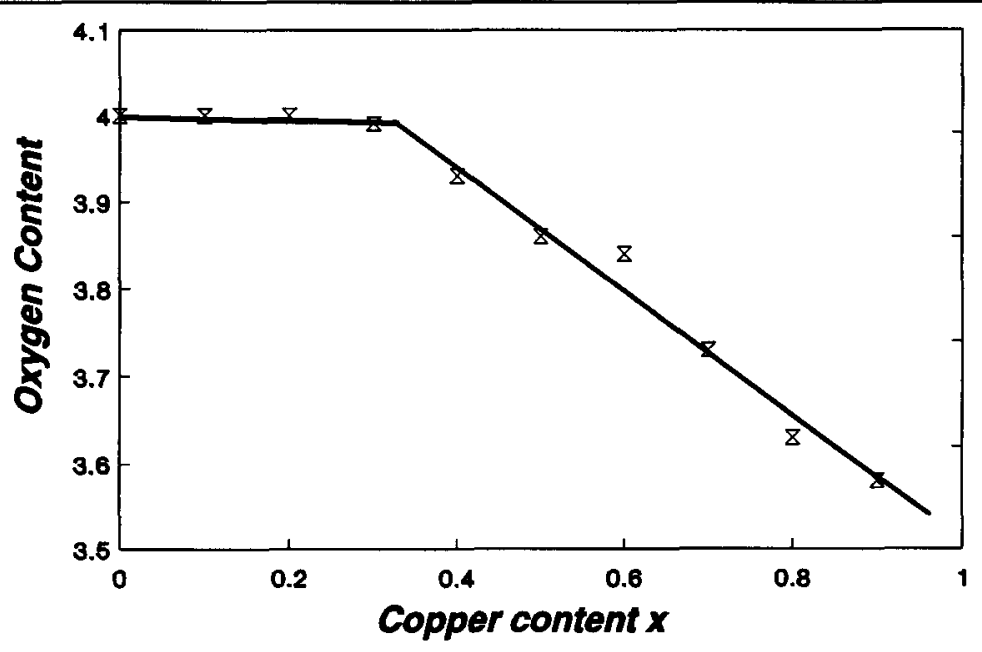

FIG. 2:

Oxygen Content as a Function of the Copper Content

TABLE II:

Refined Atomic Coordinates for $\mathrm{NdSrCoO}_{4}$

\begin{tabular}{|c|c|c|c|c|c|c|}
\hline \multicolumn{7}{|l|}{$\begin{array}{l}\mathrm{NdSrCoO}_{4} \quad 14 / \mathrm{mmm} \\
\mathrm{a}=3.7731(1) \AA \\
\mathrm{c}=12.2951(3) \AA \\
\end{array}$} \\
\hline Atom & $\begin{array}{l}\text { Wyckoff } \\
\text { symbol }\end{array}$ & $x / a$ & $y / b$ & $z / c$ & $B$ & $\mathbf{N}$ \\
\hline Nd & $4 e$ & 0 & 0 & $0.3605(1)$ & $1.44(6)$ & 2 \\
\hline $\mathrm{Sr}$ & $4 e$ & 0 & 0 & $0.3605(1)$ & $1.44(6)$ & 2 \\
\hline Co & $2 a$ & 0 & 0 & 0 & $0.9(1)$ & 2 \\
\hline$O(1)$ & $4 c$ & 0 & 0.5 & 0 & $2.3(4)$ & 4 \\
\hline$O(2)$ & $4 \mathrm{e}$ & 0 & 0 & $0.1618(11)$ & $3.3(4)$ & 4 \\
\hline $\begin{array}{ll}\text { R-factors \% } & R p \\
& \text { Rwp } \\
& \operatorname{Rexp}\end{array}$ & $\begin{array}{l}3.73 \\
4.82 \\
3.65\end{array}$ & & & & & \\
\hline
\end{tabular}

Powder Neutron Diffraction Refinements of $\mathrm{NdSrCO}_{1 \times} \mathrm{Cu}_{x} \mathrm{O}_{4 \times} \times=0.2,0.5,0.8$

As in the case of $\mathrm{NdSrCoO}_{4}$, the refinement was carried out in the space group $14 / \mathrm{mmm}$ of $\mathrm{La}_{1.85} \mathrm{Ba}_{0.15} \mathrm{CuO}_{4}$. The first stage of the refinement included only the profile parameters while later stages introduced the atomic position and the anisotropic temperature factors. As the thermogravimetric analysis data had indicated an oxygen deficiency, the occupation factors of the two oxygen sites were allowed to vary. That of $O(2)$ oscillated about 1.00 for all the compositions while that of $O(1)$ decreased from 0.99 for $x=0.2$ to 0.827 


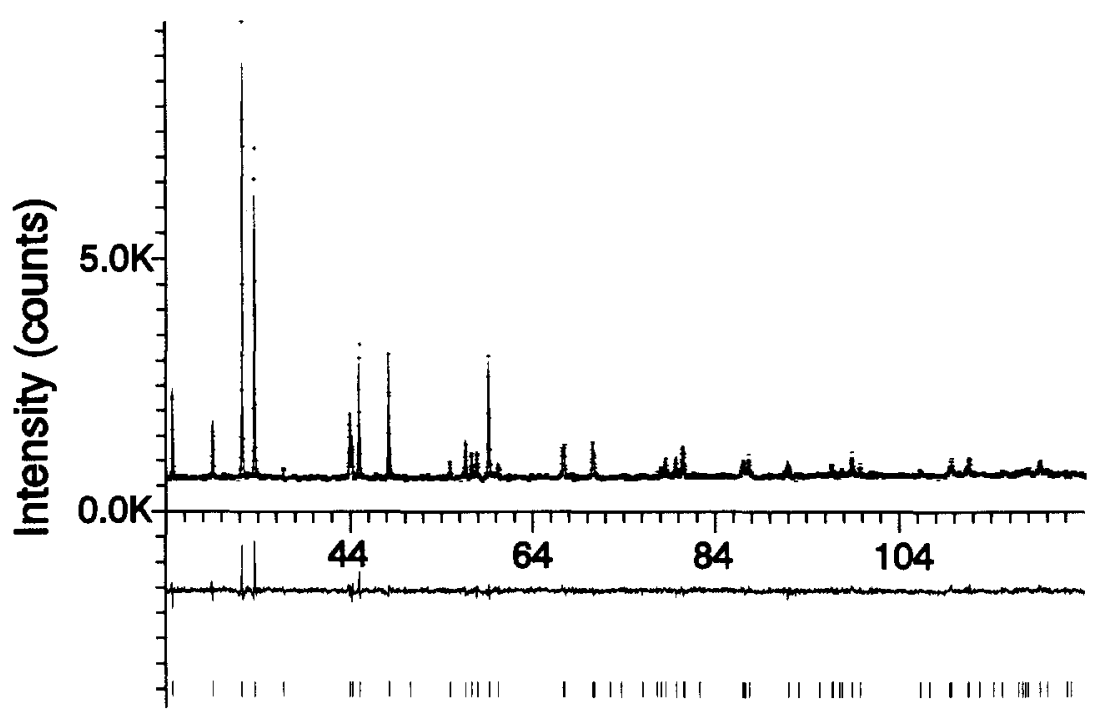

Two-Theta (degrees)

FIG. 3:

XRD Rietveld Profile Refinement of $\mathrm{NdSrCoO}_{4}$. Dots are the Observed Points, the Upper Continuous Line the Calculated Profile and the Lower Continuous Line the Difference.

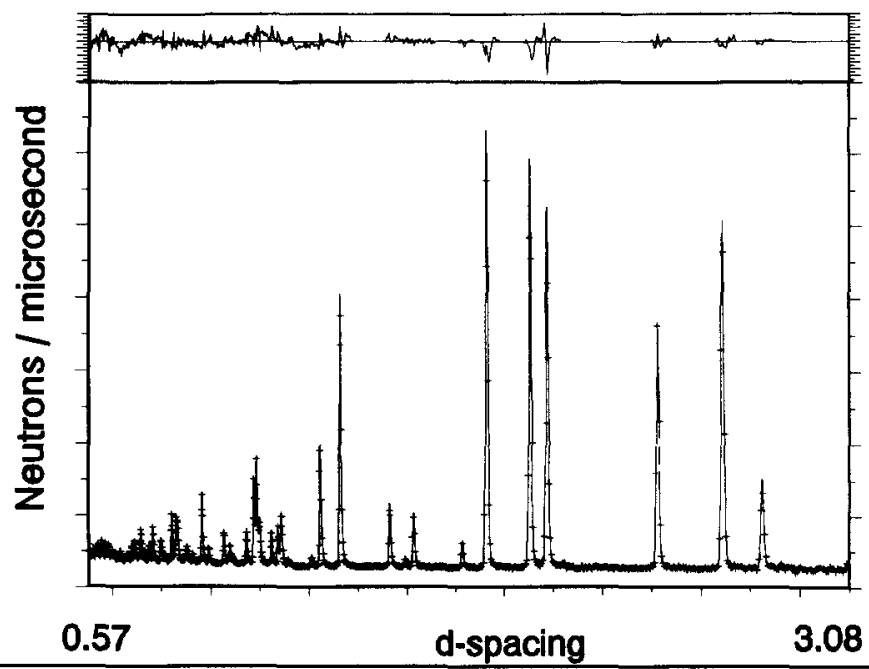

FIG. 4:

Final Profile Fit for $\mathrm{NdSrCu} \mathrm{O}_{0.5} \mathrm{Co}_{0.5} \mathrm{O}_{3.86}$. Dots are Observed Points, the Continuous Line Calculated Profile and the Upper Continuous Line the Difference on an Expanded Scale. 
for $x=0.8$. Figure 4 shows the final fit to the profile for the composition $x=0.5$. Selected results of this refinement are given in Table III as well as some relevant derived interatomic distances in Table IV.

The oxygen content drawn from the profile refinement is in very good agreement with that obtained from thermogravimetric analysis. The oxygen deficiency, which only involves the $O(1)(0,0.5,0)$ site in the $z=0$ plane, can be linked to the cell contraction observed along the a axis. The $O(2)$ position shows a significant shift with increasing copper content. This evolution inducing a $4 \%$ elongation of the $\mathrm{Cu} / \mathrm{Co}$ bond from $2.034 \AA$ for $\mathrm{x}=0.2$ to $2.121 \AA$ for $x=0.8$ can be correlate with the $4 \%$ unit-cell expansion along the $c$ axis, which is consistent with the observed difference in ionic radii of copper and cobalt.

TABLE III :

Selected Results of the PND Profile Refinement of $\mathrm{NdSrCo}_{1-x} \mathrm{Cu}_{\mathrm{x}} \mathrm{O}_{4-\gamma}$

\begin{tabular}{||ll|lll||}
\hline $\begin{array}{l}\text { Copper } \\
\text { Content } x\end{array}$ & & & & \\
\hline $\mathrm{Nd} / \mathrm{Sr}$ & $z$ & $0.36000(6)$ & $0.35948(8)$ & $0.35882(9)$ \\
\hline $\mathrm{O}(2)$ & $z$ & $0.16452(9)$ & $0.16495(12)$ & $0.1671(2)$ \\
\hline $\mathrm{O}(1)$ & occ. & $0.989(7)$ & $0.938(6)$ & $0.827(7)$ \\
\hline $\mathrm{Nd} / \mathrm{Sr}$ & $\mathrm{B} 11$ & $0.18(1)$ & $0.39(2)$ & $0.63(2)$ \\
& $\mathrm{B} 33$ & $0.31(2)$ & $0.53(3)$ & $0.61(3)$ \\
\hline $\mathrm{Cu} / \mathrm{Co}$ & $\mathrm{B} 11$ & $0.20(3)$ & $0.40(3)$ & $0.62(3)$ \\
& $\mathrm{B} 33$ & $0.79(7)$ & $0.60(5)$ & $0.91(7)$ \\
\hline $\mathrm{O}(2)$ & $\mathrm{B} 11$ & $0.96(3)$ & $1.43(3)$ & $2.04(4)$ \\
& $\mathrm{B} 33$ & $1.19(4)$ & $1.85(6)$ & $2.17(8)$ \\
\hline $\mathrm{a}$ & $\AA$ & $3.77255(2)$ & $3.76722(2)$ & $3.75154(2)$ \\
\hline $\mathrm{C}$ & $\AA$ & $12.36187(11)$ & $12.50294(11)$ & $12.69240(9)$ \\
\hline $\mathrm{R}-$ Factors $\%$ & $\mathrm{Rp}$ & 3.62 & 3.41 & 4.09 \\
& $\mathrm{Rwp}$ & 2.59 & 2.57 & 3.12 \\
& $\mathrm{Ri}$ & 4.51 & 4.75 & 6.51 \\
& $\mathrm{Re}$ & 1.47 & 1.48 & 1.11 \\
\hline \hline
\end{tabular}

As the oxidation state of neodymium and strontium remain stable, bond valence calculations were performed for the three compositions $x=0.2,0.5$ and 0.8 in order to determine the formal oxidation state for copper. The bond valence theory of Brown (15) has been extensively used to relate metal oxidation state to coordination environments in solids. Recently this theory has been employed to probe the copper oxidation state at various sites in high-temperature superconductors (16). The bond valence theory relates the oxidation state $(V)$ of a metal to the bond lengths in an analytical expression of the type $V=\Sigma\left(R_{0} / R_{i i}\right)^{N}$ where $R_{i f}$ are the various bond lengths in the coordination environment around the metal and $R_{0}$ and $\mathrm{N}$ are empirical parameters. The values of $\mathrm{R}_{0}$ and $\mathrm{N}$ used in the calculation were those relevant to $\mathrm{Cu}^{2+}$ and $\mathrm{Co}^{3+}$. They have been taken from Brown and $\mathrm{Wu}(17)$ as 1.718 and 6 . respectively, for copper and 1.687 and 6 for cobalt. The values relevant to $\mathrm{Cu}^{3+}$ given by David et al (18) lead to slightly higher oxidation states $(3.50$ for $x=0.2)$ due certainly to a lack of precise structural data for complex oxides containing $\mathrm{Cu}^{3+}$.

The bond valence calculation performed for cobalt surrounded with oxygen sites fully occupied gave an oxidation state very close to 3 for all the compositions. Introduction of an oxygen deficiency around cobalt lead to a valence of 2.60 for $x=0.8$. As far as copper is concerned, results of the calculation are given in Table $V$. The first column gives the results 
of the copper valence calculation according to the Brown theory for the oxygen deficiency on the $z=0$ plane without any distinction between cobalt and copper atoms. The second one shows the result of the same calculation for the oxygen deficiency still in the $z=0$ plane,

TABLE IV :

Selected Bond Lengths.

\begin{tabular}{|lllll|}
\hline $\begin{array}{l}\text { Copper } \\
\text { Content x }\end{array}$ & $x=0.2$ & $x=0.5$ & $x=0.8$ \\
\hline $\mathrm{Cu} / \mathrm{Co}-\mathrm{O}(1) \AA$ & $\mathrm{x} 4$ & 1.8863 & 1.8836 & 1.8758 \\
\hline $\mathrm{Cu} / \mathrm{Co}-\mathrm{O}(2) \AA$ & $\mathrm{x} 2$ & 2.0338 & 2.0624 & 2.1208 \\
\hline $\mathrm{Nd} / \mathrm{Sr}-\mathrm{O}(1) \AA$ & $\mathrm{x} 4$ & 2.5599 & 2.5758 & 2.5941 \\
\hline $\mathrm{Nd} / \mathrm{Sr}-\mathrm{O}(2) \AA$ & $\mathrm{x} 1$ & 2.4165 & 2.4322 & 2.4335 \\
\hline $\mathrm{Nd} / \mathrm{Sr}-\mathrm{O}(2) \AA$ & $\mathrm{x} 4$ & 2.6848 & 2.6813 & 2.6730 \\
\hline
\end{tabular}

but only surrounding the copper atoms (ie assuming the oxygen sites around cobalt are fully occupied). In that case the occupation factor was weighted as a function of the concentration in copper to keep the same average occupation factor as that drawn from neutron-diffraction refinements. The last column shows the results drawn from TGA for all $\mathrm{Co}$ as $\mathrm{Co}^{3+}$. In all cases a difference between the calculated values and those drawn from the TGA results was observed.

TABLE V:

Copper Bond Valence Calculated and Drawn from TGA

\begin{tabular}{||llll||}
\hline $\begin{array}{l}\text { Copper } \\
\text { Content } x\end{array}$ & $\begin{array}{l}\text { Copper valence calculation at } \\
\text { random oxygen distribution } \\
\text { between Cu and Co }\end{array}$ & $\begin{array}{l}\text { Copper valence } \\
\text { calculation } \\
\text { assuming } \mathrm{Co}^{3+}\end{array}$ & $\begin{array}{l}\text { Copper valence } \\
\text { from TGA } \\
\text { assuming } \mathrm{Co}^{3+}\end{array}$ \\
\hline 0.2 & 3.02 & 2.92 & 3.00 \\
\hline 0.5 & 2.87 & 2.72 & 2.44 \\
\hline 0.8 & 2.55 & 2.45 & 2.07 \\
\hline
\end{tabular}

It should be noted that the diffraction technique gives only the average view of each cell and does not allow differentiation of the two $\mathrm{Cu}-\mathrm{O}$ and $\mathrm{Co}-\mathrm{O}$ distances, which introduces an error into the valence calculation. However, the results of the calculation for full occupancy around cobalt (ie assuming $\mathrm{Co}^{3+}$ ) are in better agreement with the TGA results than those calculated for a random distribution.

The variations in lattice parameters, $\mathrm{O}(2)$ positions, $\mathrm{O}(\mathrm{i})$ occupancy factor and $\mathrm{Cu} / \mathrm{Co}$ $O(2)$ bond lengths as a function of $x$ show good correlation with the measured changes in oxygen stoichiometry/transition-metal content. Assuming that the cobalt content is almost certainly to be in the tripositive state, the evolution of the formal oxidation state of the copper as a function of the composition shows that it is close to 3 for the lowest contents of copper and decreases regularly for $x>0.4$ to reach 2.07 for $\mathrm{NdSrCo}_{0.1} \mathrm{Cu}_{0.9} \mathrm{O}_{4-\gamma}$.

Even the lowest content of cobait in $\mathrm{Nd}_{2} \mathrm{CuO}_{4}$ induces a change to the $\mathrm{La}_{2} \mathrm{CuO}_{4}$ structural type and seems to stabilize the copper in a high oxidation state. However structural studies, using techniques such as XRD or PND, of compounds that accommodate different atom types on the same site will observe only an average of the local oxygen environment. An EXAFS study of the copper as well as the cobalt environment, which could lead to a more accurate view of the true structure, is in progress. 


\section{Conclusions}

Copper can be successfully substituted in place of cobalt in the parent compound $\mathrm{NdSrCoO}_{4}$ up to a limit of $x=0.9$. The evolution of the cell parameters shows two main regions. Under $x=0.4$, the a parameter and especially the $c$ parameter demonstrate a slight increase while the oxygen content remains unchanged. Over $x=0.4$, the incorporation of additional copper in the structure results in a greater increase in the $c$ parameter with a reduction of the oxygen level solely in the $z=0$ plane with a concomitant slight decrease in the a parameter. Bond valence calculations show that copper in all cases has an oxidation state between two and three.

The two regions of behaviour are allied to changes in the oxidation states of the two transition metals and probably their co-ordination preferences in various spin states. Cobalt is readily oxidised to $3+$ and may take high or low spin distributions in octahedral sites in complex oxides (19); copper is less readily oxidised to the trivalent state and is frequently found in square planar co-ordinations typical of $d^{8}$ ions. The interplay of these effects plus the likely disorder in cobalt and copper distributions leads to a complex interplay of structural parameters. Whilst diffraction methods are able to determined bulk structural variations in such complex oxides a full picture of the oxygen distribution requires a local environment probe such as EXAFS. Differences in the co-ordination geometries of cobalt (in various spin states ) and copper couid then be ascertained. The results presented in this paper show that doping into complex oxides can produce quite different oxide co-ordination environments for the dopant and substituted ions; the latter may also change spin state. Such factors need to be taken into account when considering, for example, dopant studies of high temperature superconductors.

\section{Acknowledgments}

We thank the SERC for the provision of a grant. We also thank ISIS Rutherford Appleton Laboratory for the provision of neutron facilities.

\section{References}

1. J.G. Bednorz and K.A. Muller, Z. Phys. B 64, 189 (1986).

2. C.N.R. Rao, D.J. Buttrey, N. Otsuka, P. Ganguly, H.R. Harrison, C.J. Sandberg and J.M. Honig, J. Solid State Chem. 52, 266 (1984).

3. D.J. Buttrey, J.M. Honig and C.N.R. Rao, J. Solid State Chem. 64, 287 (1986).

4. N. Nguyen, J. Choisnet, M. Hervieu and B. Raveau, J. Solid State Chem. 414, 161 (1981).

5. R.A. Mohan Ram, P. Ganguly and C.N.R Rao, Mat. Res. Bull. 23, 501 (1988).

6. D. Hohlwein, A. Hoser, J. Inringer, A. Kuster, J.K. Maichle, W. Pandl, H.Ritter, S. Kemmler-Sack, R. Kiemel, W. Schafer, A. Hewat and T. Wroblewski, Zeitschrift. fur Phys. B 75, 439 (1989).

7. Von Hk. Muller-Buschbaum and W. Wollschlager, Z. Anorg. Allg. Chem. 414, 76 (1975).

8. K. Takahashi, B.Okai, M. Kosuge and M. Ohta, Jpn. J. Appl. Phys. 27, L1374 (1988).

9. M.V. Kniga, I.I. Vygovskii and E.E. Klementoviah, Russ. J. Inorg. Chem. (Engl. Transl) 24, 652(1979).

10. H.M. Rietveld, J. Appl. Crystallogr. 2, 265 (1969).

11. R. Cywinski, Polaris RAL Report (1987)

12. M.J. Johnson and W.I.F. David RAL Report $81 / 112$ (1985)

13. A.W. Hewat, Harwell report AERE-R7350 (1973)

14. L. Koester and W. B. Yelon, Netherlands Energy Research Foundation, The Netherlands

15. I.D. Brown, Chem. Soc. Rev. 7(3), 359 (1978).

16. A.W. Hewat, E.A. Hewat, J. Brynestad, M.A. Hook and E.D. Specht, Phys. C 152, 438 (1988).

17. I.D. Brown and K.K. Wu, Acta Crystallogr. B 32, 1957 (1976).

18. W.I.F. David, W.T.A. Harrison, J.M.F. Gunn, O. Moze, A.K. Soper, P. Day, J.D. Jorgensen, D.G. Hinks, M.A. Beno, L. Solderholm, D.W. Capone II, I.K. Schuller, C.U. Segre, K. Zhang and J. D. Grace, Nature (London) 327, 310 (1987).

19. J Grenier, S.Ghodbane, G Demazeau, M.Pouchard and P.Hagenmuller. Mat.Res.Bull, 14, 831 (1979). 